\title{
Correction to: An effective solution to numerical and multi-disciplinary design optimization problems using chaotic slime mold algorithm
}

\author{
Dinesh Dhawale ${ }^{1,2} \cdot$ Vikram Kumar Kamboj $^{1,4} \cdot$ Priyanka Anand $^{3}$
}

Published online: 27 July 2021

๑) Springer-Verlag London Ltd., part of Springer Nature 2021

\section{Correction to: Engineering with Computers} https://doi.org/10.1007/s00366-021-01409-4

In the original publication of the article, the second author Vikram Kumar Kamboj second affiliation has been incorrectly published. The correct second affiliation is Schulich School of Engineering, University of Calgary, Alberta, Canada.

The original article has been corrected.

Dinesh Dhawale

ddhawale56@gmail.com

Vikram Kumar Kamboj

dr.vikram.research@gmail.com

1 School of Electronics and Electrical Engineering, Lovely Professional University, Phagwara, Punjab, India

2 Department of Electrical Engineering, Priyadarshini College of Engineering, Nagpur, Maharashtra, India

3 Department of Electronics and Communication Engineering, Bhagat Phool Singh Mahila Vishwavidyalaya, Khanpur Kalan, Haryana, India

4 Schulich School of Engineering, University of Calgary, Alberta, Canada 